\title{
FIELD: A Software Tool That Integrates Harvester Data and Allometric Equations for a Dynamic Estimation of Forest Harvesting Residues
}

\author{
Heesung Woo ${ }^{1,2}\left(\mathbb{D}\right.$, Mauricio Acuna ${ }^{3}(\mathbb{D})$, Byoungkoo Choi ${ }^{4, *}$ and Sang-kyun Han ${ }^{4, *(D)}$ \\ 1 Human Resources Development Center for Covergence of Advanced Technologies in Forest Industry, \\ Kangwon National University, Chuncheon 24341, Korea; whs1608@gmail.com \\ 2 College of Forest and Environmental Sciences, Kangwon National University, Chuncheon 24341, Korea \\ 3 Forest Industries Research Centre, University of the Sunshine Coast, Locked Bag 4, Maroochydore DC, \\ Queensland 4558, Australia; macuna@usc.edu.au \\ 4 Division of Forest Sciences, Kangwon National University, Chuncheon 24341, Korea \\ * Correspondence: bkchoi@kangwon.ac.kr (B.C.); hsk@kangwon.ac.kr (S.-k.H.)
}

check for updates

Citation: Woo, H.; Acuna, M.; Choi, B.; Han, S.-k. FIELD: A Software Tool That Integrates Harvester Data and Allometric Equations for a Dynamic Estimation of Forest Harvesting Residues. Forests 2021, 12, 834. https://doi.org/10.3390/f12070834

Academic Editor: Gianni Picchi

Received: 13 May 2021

Accepted: 22 June 2021

Published: 24 June 2021

Publisher's Note: MDPI stays neutral with regard to jurisdictional claims in published maps and institutional affiliations.

Copyright: (c) 2021 by the authors. Licensee MDPI, Basel, Switzerland. This article is an open access article distributed under the terms and conditions of the Creative Commons Attribution (CC BY) license (https:/ / creativecommons.org/licenses/by/ $4.0 /)$.

\begin{abstract}
On an international comparison basis, Australia's utilisation of forest residues remains very low. While there are numerous factors contributing to this low utilisation, this is greatly explained by the limited timely and accurate data on availability, quality, and location of residues generated during harvesting operations. This manuscript reports on the development and testing of a new freeware tool called FIELD (Forest Inventory Electronic Live Data), which supports the real-time monitoring and estimation of forestry harvesting residues. As inputs, FIELD uses StanForD pri files and geo-location data extracted from the harvester's onboard computer in combination with locally developed species-specific allometric equations. Using a case study, this paper describes how FIELD works operationally and illustrates the range of support features that the tool can provide to decision-makers by producing real-time data on the availability, quality, and location of harvesting residues. In addition, it is discussed how the tool can contribute to supporting decisions during forest operations associated with the feasibility of residue utilisation in specific site conditions. Our results show that it is possible to estimate the availability of harvesting residues at geo-located sites dynamically, although further testing of the tool is required for a more accurate estimation and monitoring of harvesting residues.
\end{abstract}

Keywords: real-time monitoring; precision forestry; biomass energy; logging residues; unstructured harvester data; StanForD

\section{Introduction}

Previous research on biomass availability in Tasmania, Australia, has revealed that the amount of forest residues generated during harvesting operations has not been well estimated, which has impacted the utilisation and commercialisation of these products. In addition, stocks of forest harvesting residues has been computed using basic assumptions and factors; these include biomass recovery rates of timber harvesting from timber growth or annual increment rates [1-4] and empirical data from frontline personnel [5,6], which are inaccurate and of limited use in practical biomass planning. Related to the latter, it is critical to improve the accuracy and quality of data and information [7]. In previous studies conducted in Tasmania, forest residue estimation models have been developed separately by two organisations: Sustainable Timber Tasmania (STT), with a focus on public native forests and plantations [8-10], and Private Forests Tasmania (PFT) with a focus on private native forests and plantations $[3,11]$. However, the biomass stock prediction models have been derived using rough and general assumptions. Consequently, the estimates are difficult use in planning and managing the biomass resources, which has resulted in 
uncertainty regarding biomass stocks and has affected decision making along the biomass supply chain $[7,12,13]$.

In general, there are two major methods to estimate biomass availability. The first one is the direct destructive method, which is known for being the most accurate biomass estimation measurement [14]. This method combines the line-intersect method, a counting procedure of the above-ground biomass materials, and weight determination in the field for the different tree components (branches, leaves, trunk, etc.) [14,15]. Despite its high level of accuracy, the application of this method is not suitable for biomass estimation at a national scale level since it is time-consuming and labour expensive [16]. Other indirect methods, such as remote sensing [17-19], a geographic information system (GIS) [20,21], and biomass estimation models [22,23], are generally used in biomass estimation at a national scale. However, the major issues with the indirect methods lie in the uncertainty associated with predictions of biomass availability and its consequences for biomass management and logistics planning.

To overcome these limitations, this research investigated the use of StanForD (Standard for Forest Machine Data and Communication) data to estimate biomass availability. Modern harvester machines adhering to StanForD and equipped with onboard computers and sensors in the harvesting heads generate timber harvesting data, including diameter at breast height (DBH), height, length of stems, and time of the operations [24,25], among others. Thus, using StanForD data in combination with allometric equations can compensate for the limitations associated with direct and indirect biomass estimation methods.

Despite its great potential, some barriers preclude the more extensive use of StanForD data for research or forest management purposes. First of all, StanForD data are only generated and accessed by a harvester head that is fitted with a controller embedded in the Onboard Computing System (OBCS) of the machines [24]. Additionally, the generated StanForD data have unstructured data format, which makes it difficult to read and interpret by the end user, and the interpretation of StanForD data requires specific software developed by machine manufacturers, which is very expensive to acquire [25]. Due to these limitations, StanForD data are very limited for their use by researchers or small forest companies.

During the operation of a harvester machine, more than twenty standard files are generated in the StanForD format, including apt (cross-cutting instructions), prd (production files), pri (production individual files), drf (operational monitoring data), and stm (individual stem data) files [26]. Pri files comprise detailed production data of each harvested tree and corresponding cut logs, including all diameter sections measured at $10 \mathrm{~cm}$ intervals, $\mathrm{DBH}$, individual log volume, stem volume, log classification, stem identification number, and commercial height [27]. The use of pri files has the following fundamental benefits in comparison to prd and apt files [28]:

- It is possible to aggregate the production results from different harvesters using different apt files;

- Information from each individual log is available, not only averages per assortment;

- It is possible to convert a pri file into a prd file if an apt file is available but not vice versa;

- Information from each individual tree is available, making it possible to "reconstruct" the harvested stand.

Recognising the benefits of using pri files, the study investigated their use to estimate the availability of residues after harvesting. Currently, harvesters equipped with a global positioning system (GPS) can collect geospatial information on the location of individual trees during forest harvesting operations. When harvester machines are equipped with a GPS sensor, pri files include a locational geo-coordinate which matches with the identification number of individual trees.

We developed the Forest Inventory Electronic Live Data (FIELD) software to analyse StanForD pri files and implement a real-time geospatial harvesting residue monitoring system. Biomass availability after harvesting was estimated using suitable allometric 
equations from previous studies, such as the ones developed by Forrest [29] and Feller [30] in Tasmania and other regions of Australia. Additionally, biomass availability estimated by the FIELD software was compared and validated with results obtained from other biomass estimation methods. Thus, this study aims to demonstrate the usefulness of StanForD files to estimate biomass availability after harvesting.

\section{Materials and Methods}

\subsection{Study Site}

The study site covered a range of typical Australian Radiata pine (Pinus radiata) plantations in the Dorset region of Tasmania, which are managed by the forest company Timberland Pacific Logging (Figure 1). The study area consisted of a clear-felling operation of approximately 17.9 ha, in which 7823 trees were felled and processed during the trial. The age of the stand was 30 years old, and the stocking density in the study area was 437 trees per ha.
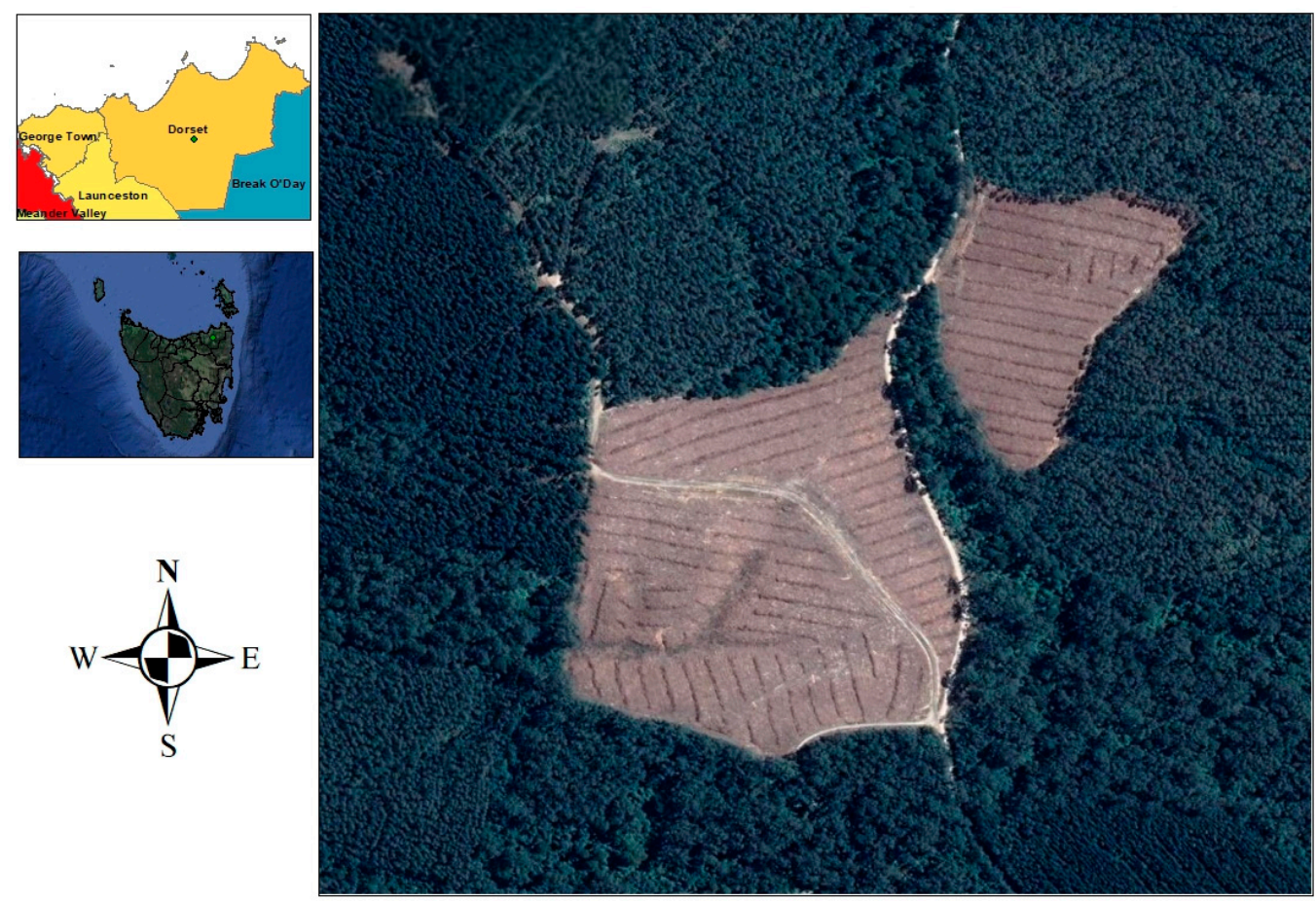

Figure 1. Case study area located in the Dorset region, Tasmania.

The harvester head collected the diameter and length from every single stem during processing. In this research, tree diameters were automatically collected from the top and middle portions of the processed stems (Figure 2). The mean diameter was $277 \mathrm{~mm}$ and $298 \mathrm{~mm}$ in the top and middle portions of the processed stems, respectively (Figure 3). The harvester machine was equipped with an on-board computer system (OBCS) fitted by the manufacturer of the harvester machine. Specifically, a harvesting head Waratah PLC-H005 was equipped with a Timbermatic, CDM 2.8 controller, and the OBCS software Silvia 5.0.

\subsection{Development of the FIELD Software Tool for Real-Time Harvesting Residue Monitoring}

The overall research workflow is presented in Figure 4. StanForD data were collected and provided by forest contractors and the forest company (Timberland Pacific Logging Co, Tasmania, AU). The Waratah H270 Series II harvester head (Waratah, Kamloops, BC, Canada) and Timber-matic controller (John Deere, Moline, IL, US) had been used for this research. Using a harvesting head fitted with a GPS sensor, the location (longitude and latitude) of individual tree stump data was collected automatically. The prototype version of the FIELD tool was programmed with the Python language. However, the 
latest version of FIELD software was developed in C\# with MSI (installer package file format used by Microsoft Windows OS) format. The FIELD tool was tested in the field and in the office to find any issues with the prototype model. Issues arisen from these tests provided valuable information to researchers and information and communications technology (ICT) technicians, allowing them to develop an improved version of the tool. During this process, the FIELD tool was tested and upgraded multiple times to improve the embedded functions and graphic user interface.
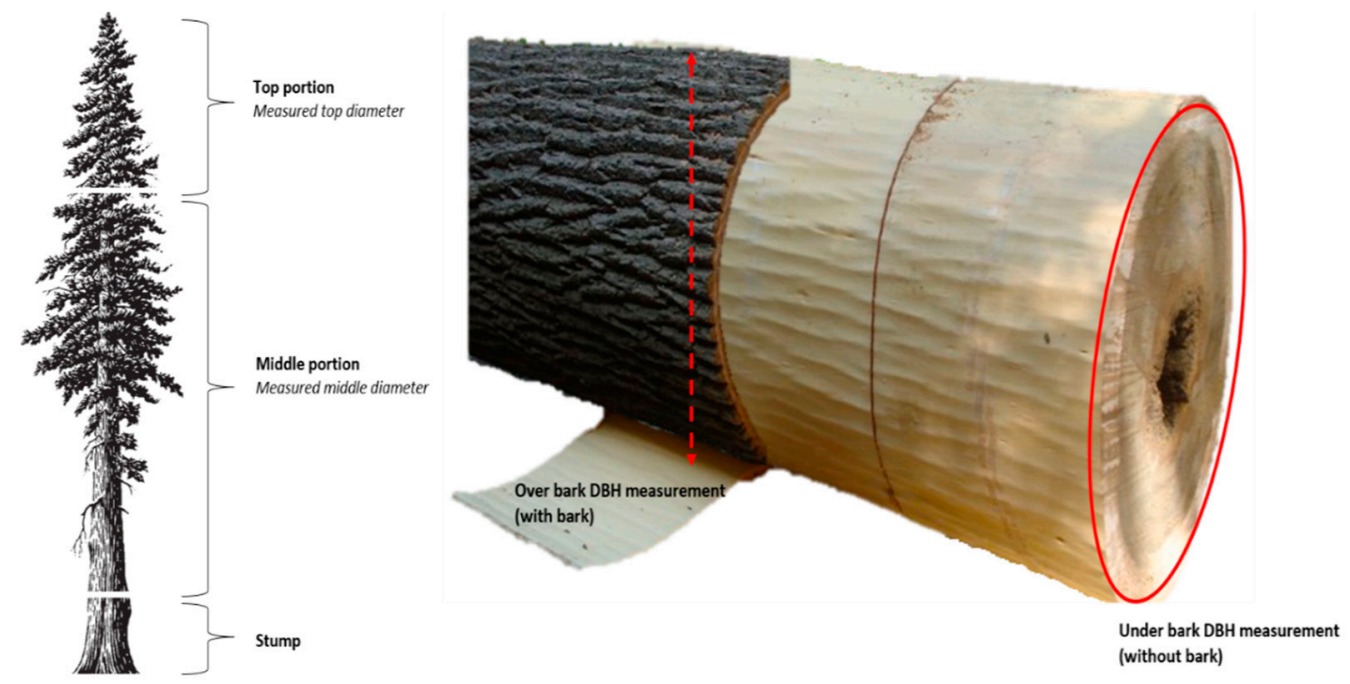

Figure 2. Over and under bark diameters measured with the harvest machine head (Source: adapted from www.archdaily.com, accessed on 12 June 2019).

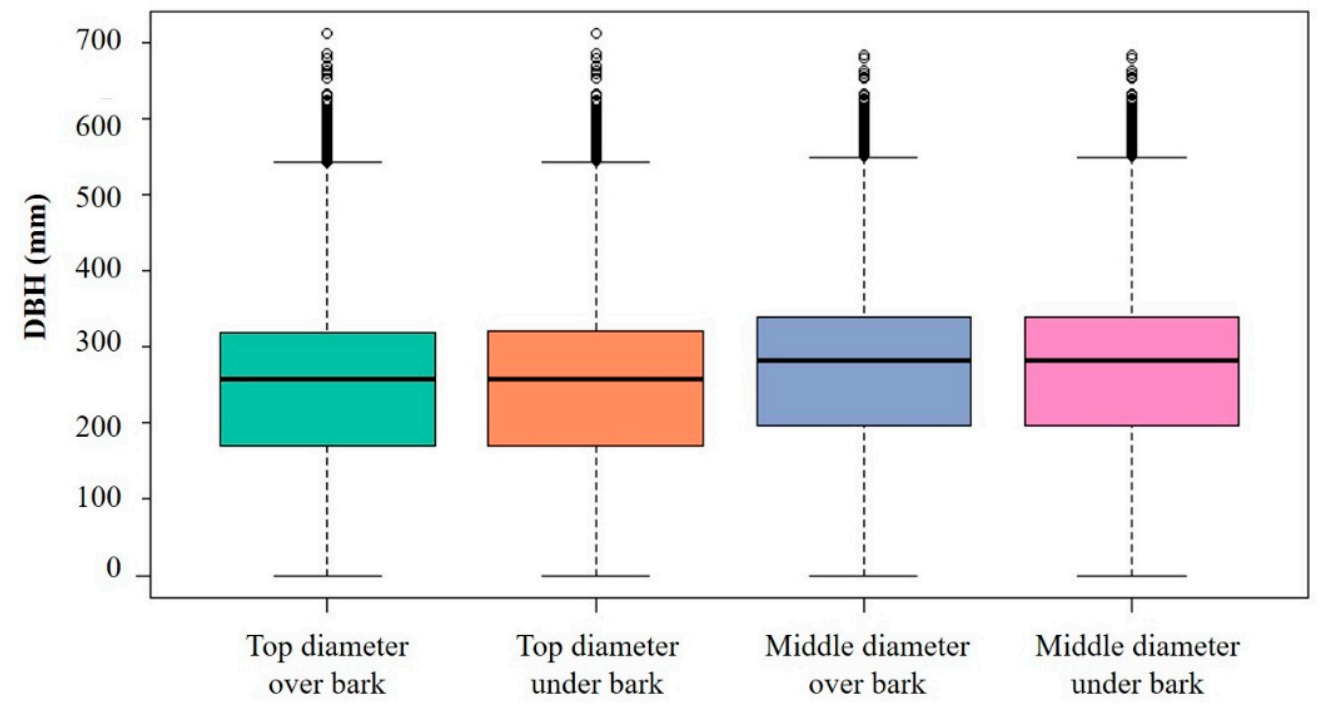

Figure 3. DBH box and whisker plot of processed stems in the study area.

The case study was conducted using quantitative data analysis. Biomass availability was estimated using developed allometric equations and DBH data from the harvester head. Geographic information, including individual tree information and estimated biomass availability, was added to the biomass availability map using the Google Maps Platform. Additionally, a timber productivity model (tree volume vs. diameter) was developed through linear regression.

Forest inventory data such as $\mathrm{DBH}$, tree length, tree number, volume, and individual tree geo-coordinate were stored in the pri file. In addition, most of the allometric equations to estimate biomass availability were developed from forest inventory data (DBH and tree 
height). In this context, the study focused on using pri files (processed with the FIELD tool) and allometric equations to predict forest biomass availability. Table 1 shows the data used to estimate biomass availability and create productivity maps.

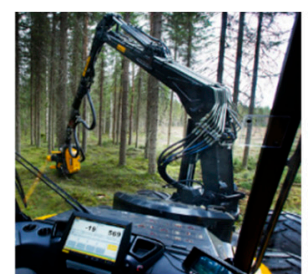

1. Data collection

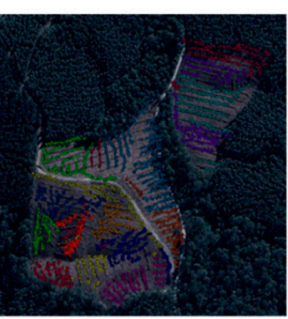

8. Residue estimation map

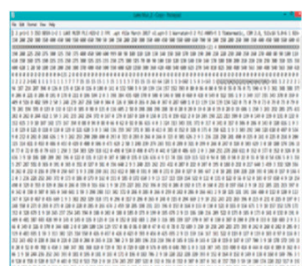

2. Import raw data (unstructured)

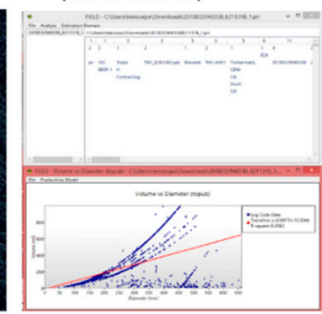

7. Data analysis(Tree volume prediction model using $\mathrm{DBH}$ )

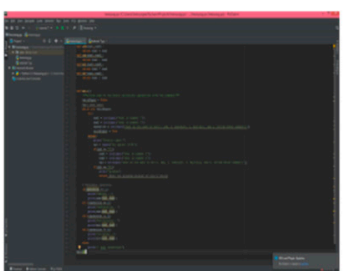

3. Developing software

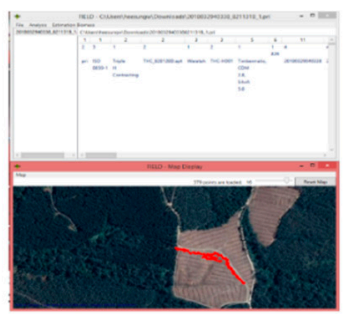

6. Data analysis(mapping and estimation harvesting residue)

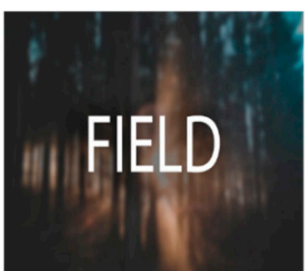

4. Prototype test

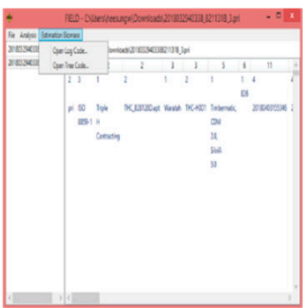

5. Converting data structure (unstructured to structured)

Figure 4. Diagram with the overall research process.

Table 1. Description of the forest inventory data in pri file (identification number of variables and definition).

\begin{tabular}{cc}
\hline Variable Number & Definition \\
\hline 201 & Diameter over bark of the top section $(\mathrm{mm})$ \\
202 & Diameter under bark of the top section $(\mathrm{mm})$ \\
203 & Diameter over bark of the middle section $(\mathrm{mm})$ \\
204 & Diameter under bark of the middle section $(\mathrm{mm})$ \\
301 & Physical stem length, $(\mathrm{cm})$ \\
401 & Solid volume over bark $\left(\mathrm{m}^{3}\right)$ \\
402 & Solid volume under bark $\left(\mathrm{m}^{3}\right)$ \\
403 & Volume over bark of the top section $\left(\mathrm{m}^{3}\right)$ \\
404 & Volume under bark of the top section $\left(\mathrm{m}^{3}\right)$ \\
500 & Stem number. Unique stem id used for all types of stems \\
501 & Log number in stem (e.g., 1st log $=1,2$ nd $=2$, and 3rd $=3)$ \\
\hline
\end{tabular}

To validate the results obtained with the FIELD tool, converted structured data were compared to commercial software (Timan 2.1-Tool for wood analysis) able to open and read StanForD pri files. After this validation, the final version of the FIELD tool was developed and deployed (Figure 5).

\subsection{Estimation of Biomass Availability Using Local Allometric Equations and StanForD Data}

Processed data from StanForD pri files, $\mathrm{DBH}$ and location of individual tree data were extracted to predict harvesting residue. Given that the allometric equations were specific for the vegetation types and range of tree sizes from which they were derived, their application to broad vegetation types may be associated with significant differences in predicted values [31]. To minimise errors when using allometric equations, their application must be performed carefully, making sure they match with tree size, age of stands, and general environmental conditions [32-34]. In our study, above-ground biomass (kg), leaves $(\mathrm{kg})$ and branches $(\mathrm{kg})$ were estimated using integrated allometric equations and StanForD data at the individual tree level. 


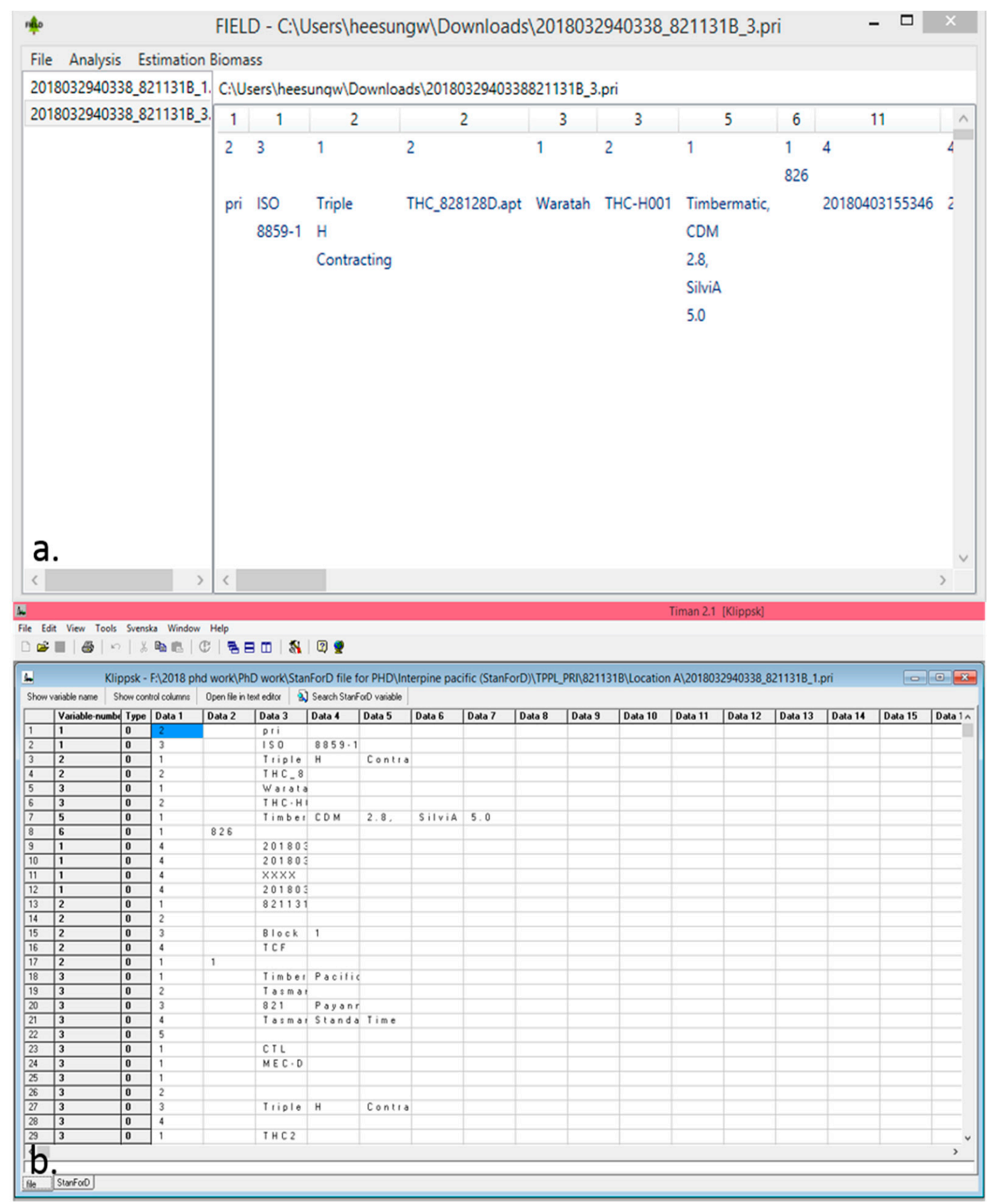

Figure 5. FIELD software validation compared to Timan 2.1 commercial software ((a) pri file open with FIELD software, (b) pri file open with Timan 2.1 commercial software).

The selection of suitable Australian-based allometric equations were reviewed to identify general environmental conditions matching those of the study area. Thus, it was possible to apply only a few of these equations in the case study area. In this context, Forrest [29] and Feller [30] equations were considered suitable for the age of stands and general environmental conditions present in the study area (Table 2) [29,30]. By combining the estimated biomass availability and individual tree location data, the FIELD tool produced a biomass availability map using the Google map platform (Figure 6). 
Table 2. Allometric equations employed and estimated total harvesting residue in the case study (Equations were developed by Forrest 1969 and Feller 1984).

\begin{tabular}{ccc}
\hline & Forrest (1969) & \\
\hline Biomass Type & Equations & $\mathbf{R}^{\mathbf{2}}$ \\
\hline $\begin{array}{c}\text { above ground } \\
\text { leaves } \\
\text { branches }\end{array}$ & $\ln \mathrm{M}=-2.1+2.3 \times \operatorname{lnDBH}$ & 0.98 \\
& $\ln \mathrm{M}=-7.5+3.3 \times \operatorname{lnDBH}$ & 0.97 \\
\hline $\ln \mathrm{M}=-0.8+3.3 \times \operatorname{lnDBH}$ & 0.94 \\
\hline stem & Feller $(1984)$ & 0.96 \\
leaves & $\mathrm{M}=5.0+171.3 \times \mathrm{D}^{2} \times \mathrm{H}$ & 0.99 \\
branches & $\mathrm{M}=-1.2+3.2 \times \mathrm{D}^{2} \times \mathrm{H}$ & 0.98 \\
\hline
\end{tabular}

$\mathrm{M}$ is tree biomass by type (kg), for logarithmic functions (ln), DBH (diameter at breast height) is in centimetres $(\mathrm{cm})$; for functions involving D2H, both $\mathrm{D}$ (diameter at breast height) and $\mathrm{H}$ (tree height) are in metres $(\mathrm{m})$.

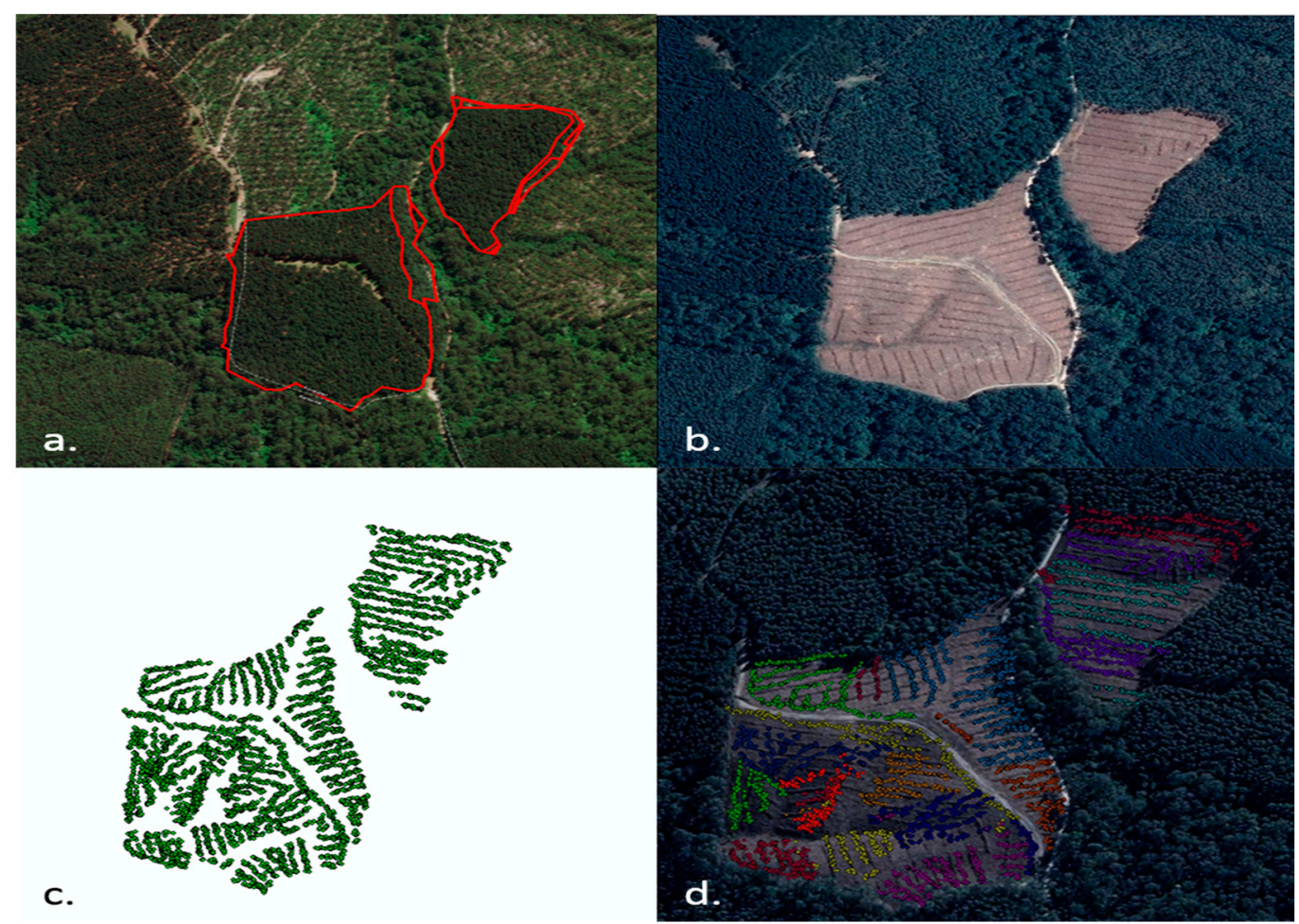

Figure 6. Map of harvesting operation generated from FIELD output data ((a) study area before harvesting operation, (b) study area after harvesting operation, (c) reconstruction and generation of biomass availability map using FIELD, (d) biomass availability map overlapped with satellite image).

Point data on the map (Figure 7) correspond to the location of individual trees. Point data attributes include DBH, tree number, geocoordinate data, and estimated biomass availability. The geo-located data generated were exported in a CSV file format and loaded into ArcGIS to develop a biomass availability database (Figure 7).

\subsection{Validation of FIELD Residue Estimation}

To validate the residue estimates provided by the FIELD tool, several methodological approaches were adopted and compared with these residue estimates. In the first approach, Forrest [29] and Feller [30] formulas were used to compare the differences between the various Radiata pine allometric equations [29,30]. In Forrest's [29] estimation procedure, only above-ground biomass and branches were factored in to estimate the available biomass material. Leaves were not included in the biomass availability calculation (due to soil nutrient issues), nor the stem wood portions such as top or offcut from timber harvesting 
calculated by Forrest [29]. The equations presented by Feller [30] were developed for radiate pine plantations in Victoria. The mean DBH and average of the stands was $29 \mathrm{~cm}$ and 37 years, respectively. In the second approach, FIELD estimates were compared with the residue models developed and provided by PFT and STT. In this validation process, the estimated state level biomass availability (PFT and STT residue solution) for the study area was obtained with ArcGIS and compared with the estimates provided by the FIELD tool. In the final step, FIELD's estimates were compared to field measurement results obtained from previous Australian harvesting residue estimation studies [35-37].

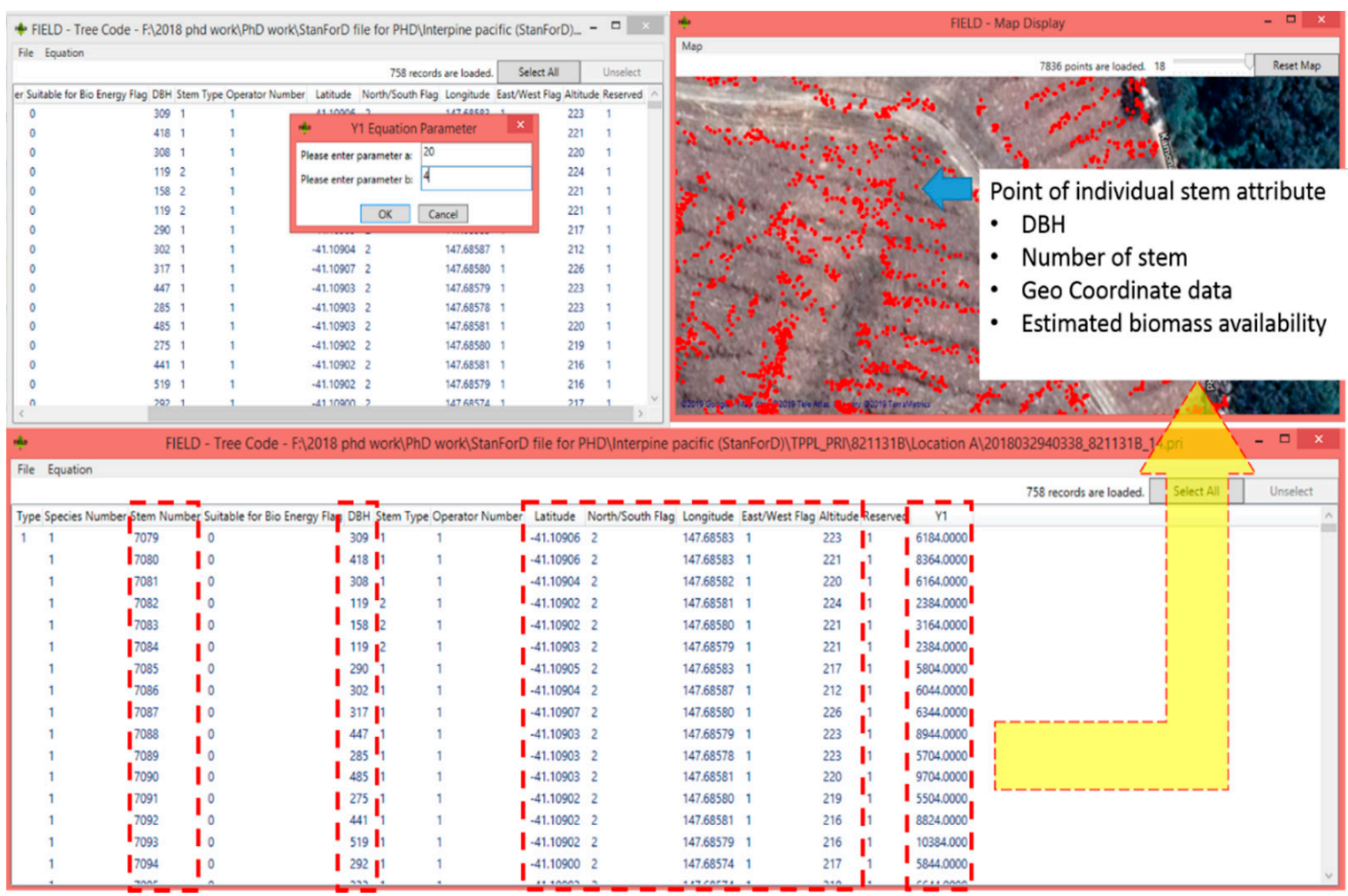

Figure 7. Real-time biomass monitoring system and biomass availability map developed by the FIELD tool.

\section{Results and Discussions}

\subsection{Harvesting Residue Estimation Using the FIELD Tool}

The geometric mean DBH value (over bark) in the study area was $37.34 \mathrm{~cm}$. The results of the estimated mean value of biomass availability by type (above ground, leaves, and branches) are shown in Table 3, while the results of the FIELD harvesting residue estimation using the Forrest [29] formula are shown in Table 2. The estimated results indicate that branches comprised the largest component of harvesting residue biomass of all types (above ground, leaves, and branches). In this study, only above-ground biomass and branches were included as a usable biomass feedstock. The estimated amount of leaves was excluded as usable biomass due to economic and soil nutrient issues. Table 3 shows that a large amount of above-ground biomass (approximately 228 green tons) and branches (304 green tons) could be used as a biomass energy source resulting from harvesting. 
Table 3. Radiata pine allometric equation and estimated total harvesting residue in the case study (equations were developed by Forrest [29] and Feller's [30]).

\begin{tabular}{|c|c|c|c|c|c|c|}
\hline \multicolumn{2}{|c|}{$\begin{array}{c}\text { Input } \\
\text { Mean } \pm \text { SD } \\
(\text { Min-Max) }\end{array}$} & \multirow[t]{2}{*}{ Biomass Type } & \multicolumn{2}{|c|}{$\begin{array}{l}\text { Estimated Biomass with Forrest } \\
\text { (1969) }\end{array}$} & \multicolumn{2}{|c|}{$\begin{array}{c}\text { Estimated Biomass with with } \\
\text { Feller (1984) }\end{array}$} \\
\hline $\mathrm{DBH}(\mathrm{cm})$ & Height (m) & & $\begin{array}{c}\text { Individual } \\
\text { tree-level (kg) } \\
\text { Mean } \pm \text { SD } \\
(\text { Min-Max) }\end{array}$ & $\begin{array}{l}\text { Stand-level } \\
(\mathrm{kg} / \mathrm{ha})\end{array}$ & $\begin{array}{c}\text { Individual } \\
\text { tree-level (kg) } \\
\text { Mean } \pm \text { SD } \\
(\text { Min-Max) }\end{array}$ & $\begin{array}{l}\text { Stand-level } \\
\quad(\mathrm{kg} / \mathrm{ha})\end{array}$ \\
\hline \multirow{5}{*}{$\begin{array}{l}37.34 \pm 8.42 \\
(10.40-61.10)\end{array}$} & \multirow{5}{*}{$\begin{array}{l}18.23 \pm 4.13 \\
(12.31-20.18)\end{array}$} & Above ground & $\begin{array}{l}415.24 \pm 240.47 \\
(26.85-1627.50)\end{array}$ & 227,964 & - & - \\
\hline & & Leaves & $\begin{array}{l}69.12 \pm 56.72 \\
(1.28-440.13)\end{array}$ & 75,874 & $\begin{array}{l}84.32 \pm 43.35 \\
(1.45-456.72)\end{array}$ & 90,374 \\
\hline & & Branches & $\begin{array}{c}159.12 \pm 156.72 \\
(2.50-887.12)\end{array}$ & 303,838 & $\begin{array}{l}695.31 \pm 208.17 \\
(24.26-1836.53)\end{array}$ & 503,488 \\
\hline & & Stem & - & - & $\begin{array}{c}625.24 \pm 213.18 \\
(17.15-1943.37)\end{array}$ & 585,013 \\
\hline & & Total & - & 607,676 & - & $1,178,875$ \\
\hline
\end{tabular}

\subsection{Validation of FIELD Residue Estimates from Allometric Equations and Previous Estimation Methods}

To validate the residue estimation, several methodological approaches were adopted, and their results were compared to those provided by the FIELD tool. As indicated previously, the Forrest [29] formula estimated 608.00 GMT of residues, whereas the Feller [30] formula estimated 1178.54 GMT of residues (Table 3). The substantial difference between these two formulas is explained primarily by the differences in stand DBH and age. Environmental variables, such as $\mathrm{DBH}$, age, location, and soil conditions, etc., in these equations, did not perfectly match those in the study area, which had an impact on the biomass estimated. Additionally, the Forrest equation underestimated the amount of residue in comparison with the Feller equation since in the latter equation, the stem wood portion was not accounted. These results revealed some limitations in residue estimation when using the FIELD tool, which was mainly due to the mismatch between the conditions of the study area and those present in the areas from where the equations were developed.

In the second validation process, the FIELD estimation employed the formula developed by Feller, and the results were compared with the residue estimates provided by PFT and STT. The results indicated that there was a substantial difference between the estimates obtained with the FIELD tool and those from PFT and STT modelling. Based on PFT and STT models, the estimated biomass availability totalled 141.02 GMT (Figure 8). These results indicate that the models developed by PFT and STT yield the lowest biomass estimates among the several biomass estimation techniques being compared (FIELD estimation and Victoria/Tasmania residue estimation study). Additionally, these results make it clear that the pre-existing biomass estimation method in Tasmania needs to be validated before being applied in operational biomass management planning.

In the final step, estimates from FIELD were validated through comparison with three previous harvesting studies in Victoria and Tasmania [35-37]. Among the three different studies (residue estimation studies in Australia, Tasmania, and Queensland regions), the "Australia pine cut-to-length" study was the one with the most similar stand conditions to that of the study area [36]. This resulted in close estimates of harvesting residues between the "Australia pine cut-to-length" study (1588.73 GMT) and estimates obtained with the FIELD tool using Feller's formula (Figure 9). However, the results from previous field studies in Australia indicated that the biomass estimates were highly affected by a number of factors such as harvesting operation method, DBH, age, and silviculture regime [38]. This resulted in differences with estimates from previous Australian field measurement 
studies, even when the estimates were calculated and compared on a GMT/ha basis. Thus, these results suggest that further studies are required to validate the estimates obtained with the FIELD tool, including those derived from the combination of actual measurements of harvesting residue and allometric equations.

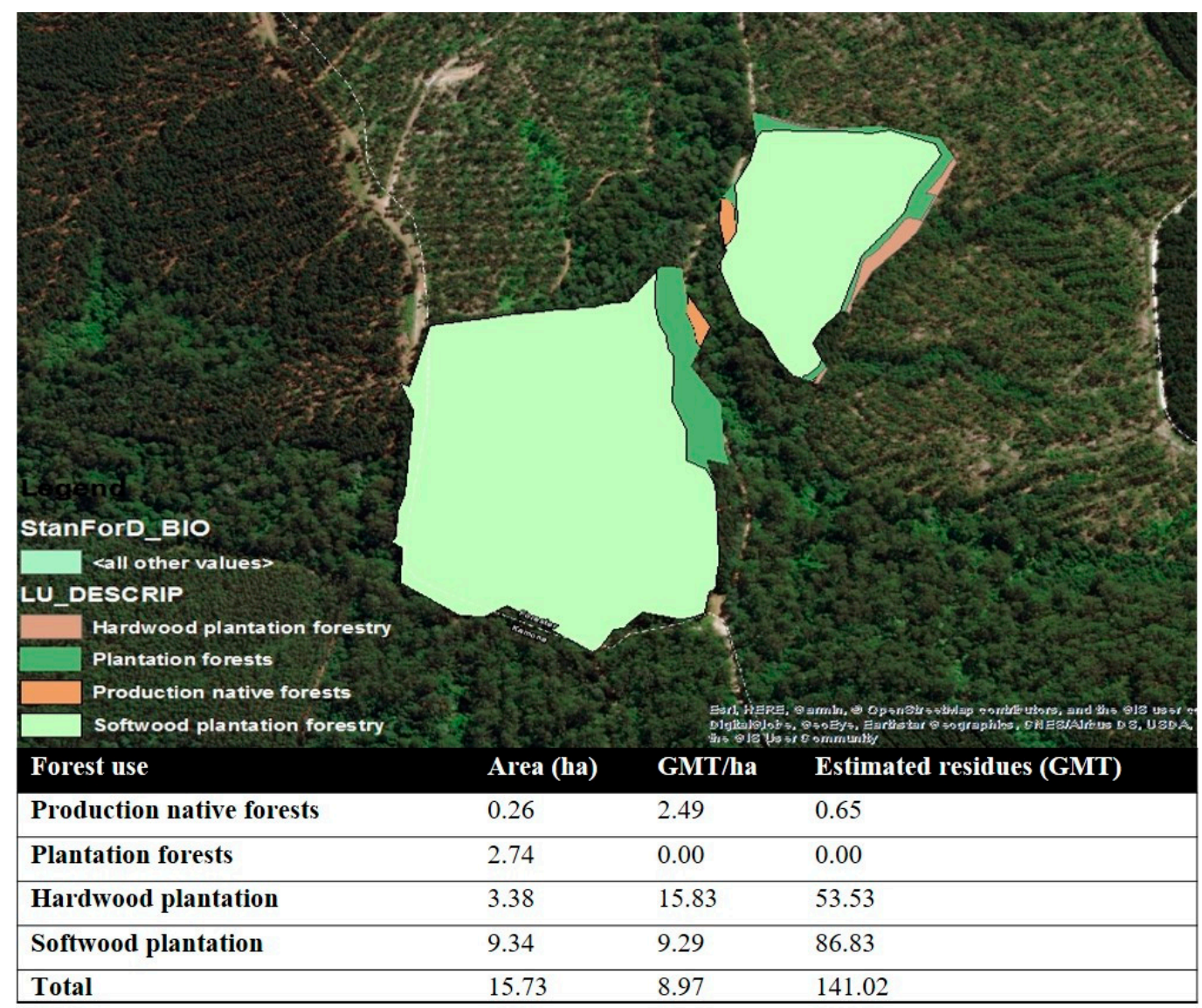

Figure 8. Estimated forest residue from PFT and STT residue models [3].

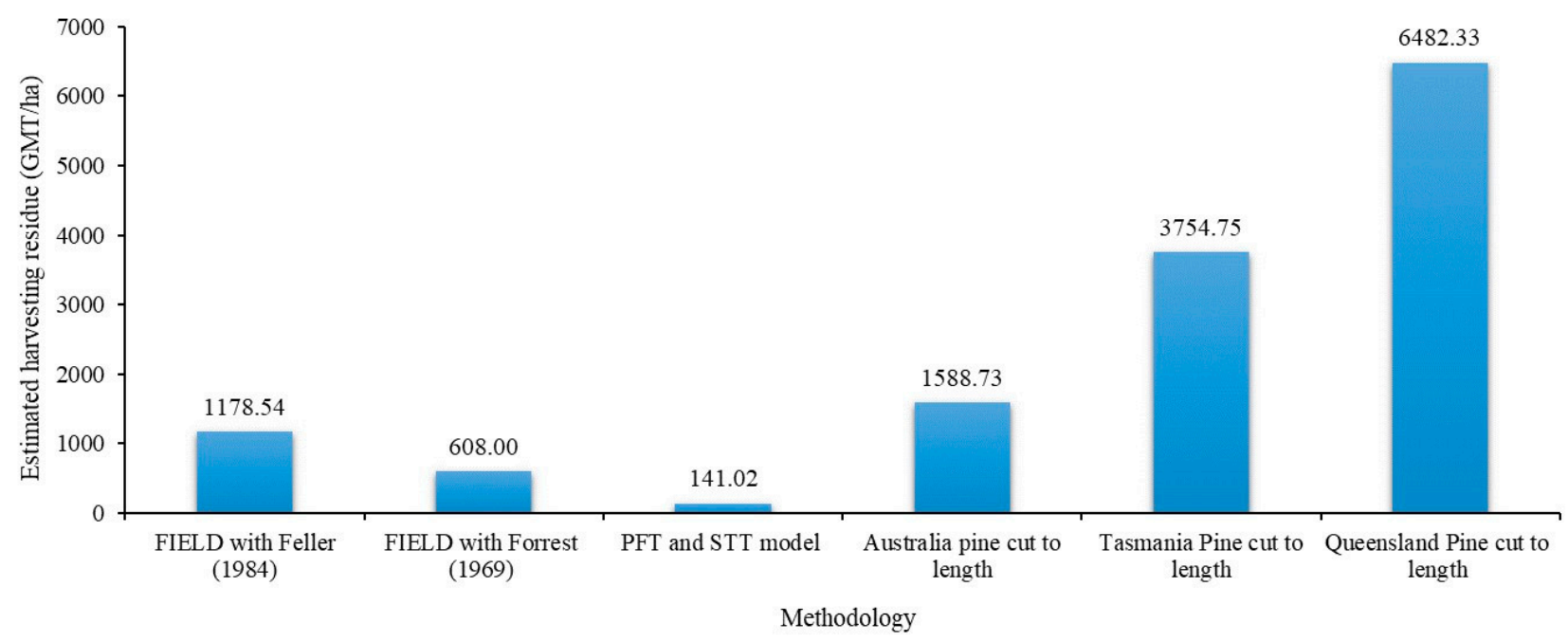

Figure 9. Harvesting residue estimates obtained with different methodological approaches.

This research investigated the digital role of improving the accuracy of forest harvesting residue estimation using ICT techniques and StanForD. However, the lack of harvester head data access and limited software validation process, the accuracy of FIELD estimation 
is not guaranteed. For these reasons, FIELD estimation needs an additional validation process such as controlled harvesting residue field measurement or developing an allometric equation in the harvesting operation site, which generated with StanForD. More importantly, the FIELD tool can generate a forest value map which includes valuable information for improving forest management and silviculture planning. The value map consists of individual tree DBH with geo-location information. The use of a combined value map and other environmental data such as soil composition, nutrients, and climate, are expected to present how different parameters affect tree growth, predict the best management plan to plant the trees or help to increase future timber productivity.

In summary, combining the results from the FIELD tool and allometric equations have shown to be a promising approach to estimate biomass availability, and with a greater potential than those obtained from conventional residue estimation methods. Results from this case study have shown that the FIELD software has the potential to be successfully used as a management or monitoring tool in practical forest planning. Additionally, the use of StanForD files allows for the cost-effective collection and reading of large samples during harvesting operations [39]. This could be a good starting point to expand forest research into big data analytics aiming at discovering unknown or unrevealed patterns from data provided by silviculture, forest management, and forest inventory systems. In the case of biomass, this will require further research to validate the use new methodological approaches that improve the accuracy of availability estimates.

\section{Limitations and Contributions of Research}

The objective of this research was to develop FIELD, which is available to read and convert unstructured data to a structured data format. Additionally, FIELD was integrated with a geographic information system to monitor real-time harvesting residue estimation to support forest and biomass-related industry managers' decision making or planning. The results of this case study demonstrated the effectiveness of using StanForD files to dynamically estimate available harvesting residues at geo-located harvesting sites while generating data on harvesting operational efficiency and productivity. The generated map consisted of a high accuracy of location-based data that can be applied into further study to investigate the logistics of haulage and utilisation of forest residues from specific locations. This investigated real-time biomass monitoring tool will be expected to support decision making about optimal locations for biomass residue utilisation for either bioenergy or EWPs. However, due to the limited software validation process, the accuracy of FIELD estimation was not validated. In a future study, the additional validation process will be required in a controlled harvesting residue field measurement site. Simultaneously, allometric equations need to be developed in a harvesting operation site, which is generated with StanForD harvester heads.

Additionally, the accuracy of collected harvester GPS information has some limitations in predicting precise individual tree locations. The location of the individual tree has not perfectly been matched with the collected GPS information. Most of the harvester head GPS sensors were attached in the harvester machine cab instead of the machine head. To overcome these limitations, Olivera (2016) investigated evaluating factors affecting harvester productivity using a GNSS attached to the harvester head. However, in general, there is a gap between actual location and the recorded geo-coordinate information of individual tree. Additionally, accessing the harvester head data is one of the biggest challenges in the use of StanForD data. Most of harvest machine operators were not familiar with entire system of harvester head generation and usage.

Due to the lack of understanding in the StanForD harvester head, the data were not collected and used adequately by operators and forest managers. For these reasons, enhancing the use of StanForD harvester head data in forest industry sector seems to require the education of forest operators and related stakeholders to understand the importance of harvester head data utilisation in improving forest management. 
Through a case study, this research describes how FIELD works and illustrates the kind of support that this tool can provide to decision-makers by producing real-time data on the availability, quality, and location of harvesting residues. It is arguably discussed that using this tool will contribute to supporting decision making around estimating the feasibility of residue utilisation logistics in specific locations. The results demonstrate that it is possible to estimate harvesting residue availability at geo-located sites dynamically, although further testing of the tool is required for the more accurate estimation and monitoring of harvesting residue.

\section{Conclusions}

This paper investigated the potential impact of ICT techniques and StanForD data to improve the accuracy of forest harvesting residue estimates. The objective of this research was to develop the FIELD tool, which enables one to read and convert unstructured data into a structured data format. Additionally, the FIELD tool was integrated with a geographic information system to monitor real-time harvesting residue estimates, and ultimately to support forest and biomass decision making by industry managers and planners.

The FIELD tool was tested in a study site located in Dorset, Tasmania, comprising a Radiata pine plantation forest. The results obtained in this study demonstrated the effectiveness of using StanForD files to dynamically estimate available harvesting residues at geo-located harvesting sites while generating data on harvesting operational efficiency and productivity. The generated map consisted of a high accuracy of location-based data, which can also be used to plan transport logistics and the mobilisation of forest residues from specific locations. As we described in the study site, the case study was conducted on an Australian Radiata pine plantation region. In general, the differences of $\mathrm{DBH}$ and tree height of plantation tree were expected to be very small. However, Figure 3 revealed that there are some outstanding individual trees in the plantation area. The generated spatial map of the FIELD tool is expected to provide efficient information for forest managers' and owners' future management plans. Both the FIELD tool and the results from this investigation are also expected to support decision making for the optimal location of biomass facilities planned to produce either bioenergy or bio-products. However, before the FIELD tool can be applied in a broader operational context, additional well-designed and controlled validation studies must be conducted. It is also essential that new allometric equations are developed from data collected in these field studies in order to supplement StandForD data that are collected with harvesting equipment.

Author Contributions: Conceptualization, H.W. and M.A.; methodology, H.W., B.C. and S.-k.H.; validation, M.A. and H.W.; formal analysis, H.W.; investigation, H.W., M.A., B.C. and S.-k.H.; resources, H.W. and M.A.; data curation, H.W. and M.A.; writing-original draft preparation, H.W.; writing-review and editing, B.C., S.-k.H. and M.A.; visualization, H.W.; supervision, M.A.; project administration, H.W.; funding acquisition, B.C. and S.-k.H. All authors have read and agreed to the published version of the manuscript.

Funding: This study was carried out with the support of 'R\&D Program for Forest Science Technology (Project No. 2020212D10-2122-AC02 and 2019151A00-2123-0301)' provided by Korea Forest Service (Korea Forestry Promotion Institute).

Institutional Review Board Statement: Not applicable.

Informed Consent Statement: Not applicable.

Data Availability Statement: Not applicable.

Acknowledgments: The authors would like to thank the ARC Centre for Forest Value, based at the University of Tasmania, for their support.

Conflicts of Interest: The authors declare no conflict of interest. 


\section{References}

1. URS. Report: Forest Residues Solution Study Stage 1-Residue Options Identification and Analysis; URS Australia Pty Ltd.: Richmond, Australia, 2015.

2. Sustainable Timber Tasmania. Forest Residue Solutions Study Stage 2-Detaild Options Analysis; Sustainable Timber Tasmania: Tasmania, Hobart, 2016.

3. Private Forests Tasmania. Residue Solution Project; Private Forests Tasmania: Hobart, Australia, 2014.

4. Wilson, J. Private Forest Resourcing Model 2012: Where are the Best Locations for a Hypothetical Tasmanian Wood Processing Plant. Unpublished Report of Esk Mapping $\mathcal{E}$ GIS to Private Forests Tasmania; Private Forests Tasmania: Tasmania, Australia, 2012.

5. Rothe, A. Forest Biomass for Energy: Current and Potential Use in Tasmania and a Comparison with European Experience; Zentrum Wald Forst Holz Weihenstephan, University of Applied Sciences, Weihenstephan-Triesdorf: Hobart, Australia, 2013.

6. Rothe, A.; Moroni, M.; Neyland, M.; Wilnhammer, M. Current and potential use of forest biomass for energy in Tasmania. Biomass Bioenergy 2015, 80, 162-172. [CrossRef]

7. Francois Cramer, M.F.; Gray, M.; Jaraczewski, S.; Kuster, J.; Shanker, P.; Vempati, A.R.; Wayne, C.; Wisbeski, L. Feasibility Report For Biomass Energy Plant In Berlin; Columbia University: New York, NY, USA, 2016.

8. Tasmania, F. Sustainable High Quality Eucalypt Sawlog Supply from Tasmanian State Forest; Forestry Tasmania: Hobart, Australia, 2007.

9. Burgman, M.; Robinson, A. Review of Tasmanian Forest Estate Wood Supply Scenarios; Final Report to the Independent Verification Group, Intergovernmental Agreement; University of Melbourne: Parkville, VIC, Australia, 2012.

10. Raison, R.; Kirschbaum, M.; McCormack, R.; Attiwill, P.; Richardson, A. Review of the Science Relevant to the Sustainable Use of Native and Plantation Forest-Harvesting Residues for Energy Production in Tasmania; CSIRO Forestry and Forest Products: Canberra, Australia, 2002.

11. Wilson, J. Dorset Woody Biomass Pre-Feasibility Study 2013: A Regional Inventory of Potential Woody Biomass Resources Surrounding Scottsdale; Private Forests Tasmania: Hobart, Australia, 2013.

12. Burak, A.; Harry, C.; David, W.; Kevin, G.; Sujith, S.; Mario, E.; Norman, S. Woody biomass and mill waste utilization opportunities in Alabama: Transportation cost minimization, optimum facility location, economic feasibility, and impact. Environ. Prog. Sustain. Energy 2011, 30, 720-732. [CrossRef]

13. Perlack, R.D. Biomass as Feedstock for a Bioenergy and Bioproducts Industry: The Technical Feasibility of a Billion-Ton Annual Supply; Oak Ridge National Laboratory: Oak Ridge, TN, USA, 2005.

14. Warren, W.; Olsen, P. A line intersect technique for assessing logging waste. For. Sci. 1964, 10, $267-276$.

15. Oneil, E.; Lippke, B. Eastern Washington Biomass Accessibility; University of Washington: Seattle, WA, USA, 2009.

16. Vashum, K.T.; Jayakumar, S. Methods to estimate above-ground biomass and carbon stock in natural forests-A review. J. Ecosyst. Ecogr. 2012, 2, 1-7. [CrossRef]

17. Wulder, M.A.; White, J.C.; Fournier, R.A.; Luther, J.E.; Magnussen, S. Spatially explicit large area biomass estimation: Three approaches using forest inventory and remotely sensed imagery in a GIS. Sensors 2008, 8, 529-560. [CrossRef] [PubMed]

18. Tomppo, E.; Nilsson, M.; Rosengren, M.; Aalto, P.; Kennedy, P. Simultaneous use of Landsat-TM and IRS-1C WiFS data in estimating large area tree stem volume and aboveground biomass. Remote Sens. Environ. 2002, 82, 156-171. [CrossRef]

19. Muukkonen, P.; Heiskanen, J. Biomass estimation over a large area based on standwise forest inventory data and ASTER and MODIS satellite data: A possibility to verify carbon inventories. Remote Sens. Environ. 2007, 107, 617-624. [CrossRef]

20. Beccali, M.; Columba, P.; D'Alberti, V.; Franzitta, V. Assessment of bioenergy potential in Sicily: A GIS-based support methodology. Biomass Bioenergy 2009, 33, 79-87. [CrossRef]

21. Montgomery, T.D.; Han, H.-S.; Kizha, A.R. Modeling work plan logistics for centralized biomass recovery operations in mountainous terrain. Biomass Bioenergy 2016, 85, 262-270. [CrossRef]

22. Cutini, A.; Chianucci, F.; Manetti, M.C. Allometric relationships for volume and biomass for stone pine (Pinus pinea L.) in Italian coastal stands. Iforest Biogeosci. For. 2013, 6, 331. [CrossRef]

23. Zhang, X.; Kondragunta, S. Estimating forest biomass in the USA using generalized allometric models and MODIS land products. Geophys. Res. Lett. 2006, 33. [CrossRef]

24. Arlinger, J.; Möller, J. Information exchange with CTL machines, recent development of StanForD-a communication standard. In Proceedings of the 3rd Forest Engineering Conference, Mont-Tremblant, QC, Canada, 1-4 October 2007; Available online: http:/ / www.feric.ca/en (accessed on 10 May 2018).

25. Roth, G. StanForD as a Data Source for Forest Management: A Forest stand Reconciliation Implementation Case Study; University of Canterbury: Canterbury, UK, 2016.

26. Olivera, A. Exploring Opportunities for the Integration of GNSS with Forest Harvester Data to Improve Forest Management. Ph.D. Thesis, University of Canterbury, Christchurch, New Zealand, 2015.

27. Räsänen, T.; Sorsa, J.-A.; Oy, M. StanForD 2010-Naming and Design Rules; Metsäteho Oy, Skogforsk: Uppsala, Sweden, 2010.

28. Arlinger, J.; Möller, J.; Sondell, J. A description of pri-files. Backgr. Struct. Ex. Work. Rep. Skogforsk 2003, 559, 12.

29. Forrest, W.G. Variations in the Accumulation, Distribution and Movement of Mineral Nutrients in Radiata Pine Plantations; Australian National University: Canberra, Australia, 1969.

30. Feller, M. Effects of an exotic conifer (Pinus radiata) plantation on forest nutrient cycling in southeastern Australia. For. Ecol. Manag. 1983, 7, 77-102. [CrossRef] 
31. Eamus, D.; Burrows, W.; McGuinness, K. Review of Allometric Relationships for Estimating Woody Biomass for Queensland, the Northern Territory and Western Australia; Australian Greenhouse Office: Canberra, Australia, 2000.

32. Fehrmann, L.; Kleinn, C. General considerations about the use of allometric equations for biomass estimation on the example of Norway spruce in central Europe. For. Ecol. Manag. 2006, 236, 412-421. [CrossRef]

33. Case, B.S.; Hall, R.J. Assessing prediction errors of generalized tree biomass and volume equations for the boreal forest region of west-central Canada. Can. J. For. Res. 2008, 38, 878-889. [CrossRef]

34. Jenkins, J.C.; Chojnacky, D.C.; Heath, L.S.; Birdsey, R.A. National-scale biomass estimators for United States tree species. For. Sci. 2003, 49, 12-35.

35. Ghaffariyan, M.; Sessions, J.; Brown, M. Machine productivity and residual harvesting residues associated with a cut-to-length harvest system in southern Tasmania. South. For. J. For. Sci. 2012, 74, 229-235. [CrossRef]

36. Ghaffariyan, M. Assessment of Harvest Residues from Different Harvesting Operation Sites in Australia; CRC for Forestry Bulletin 31, September 2012; CRC: Boca Raton, FL, USA, 2012.

37. Ghaffariyan, M.R.; Apolit, R. Harvest residues assessment in pine plantations harvested by whole tree and cut-to-length harvesting methods (A case study in Queensland, Australia). Silva 2015, 16, 1.

38. Harrill, H.; Han, H.-S. Productivity and cost of integrated harvesting of wood chips and sawlogs in stand conversion operations. Int. J. For. Res. 2012, 2012, 1-10. [CrossRef]

39. Strandgard, M.; Walsh, D.; Acuna, M. Estimating harvester productivity in Pinus radiata plantations using StanForD stem files. Scand. J. For. Res. 2013, 28, 73-80. [CrossRef] 